\title{
Teaching and Learning Science Using YouTube Videos and Discovery Learning in Primary School
}

\section{Irwan Koto}

Postgraduate Program of Elementary Education, Universitas Bengkulu, Indonesia

凶koto_irwan@yahoo.co.id

\begin{abstract}
This research aims at comparing the changes in factual, conceptual, and procedural knowledge of heat transfer in learning science using YouTube videos accompanied by discovery learning among fifth graders. A pre-and post-test experimental design was conducted by two different groups. One of the groups was randomly assigned to conduct discovery learning and YouTube videos $(n=21)$ and the others were to conduct discovery learning and hands-on activities $(n=21)$. Students in the experimental group used YouTube videos to do the assignments, whereas those in the control group used hands-on activities. Before conducting the treatment, all the students carried out the pre-test. Pre-test analyses showed that there was no significant difference between the two groups in terms of factual, conceptual, and procedural knowledge of heat transfer. The post-test was conducted by students in two groups after completing four weeks throughout the fall semester of the 2018-2019 Academic Year. The research results revealed that both groups showed various effects on the acquisition of factual, conceptual, and procedural knowledge. Well-selected and related video material could enhance student knowledge related to the concept of heat transfer.
\end{abstract}

Keywords: YouTube videos, discovery learning, factual, conceptual, procedural knowledge

How to Cite: Koto, I. (2020). Teaching and Learning Science Using YouTube Videos and Discovery Learning in Elementary School. Mimbar Sekolah Dasar, 7(1), 106-118. doi:http://dx.doi.org/10.17509/mimbarsd.v7i1.22504.

INTRODUCTION The use of video streaming media, such as YouTube (http://www.youtube.com), in the classroom learning is important to be considered as an alternative educational tool to promote students' engagements in science lessons (Jaffar, 2012). However, this potential use of video technology can affect student learning when teachers use YouTube videos directly as apart of instruction to introduce new concepts and to explain concepts during main or close instruction (Jones \& Cuthrell, 2011).

The availability of Web 2.0 technology as a new set of tools for teaching, including YouTube, has become a promising means of supporting student learning and engagement for certain reasons (Churchill, 2009). YouTube videos are not merely clips used as teaching stimulus, but they are used as learning tools (Berk, 2009). The integration of YouTube videos in the learning process supports students' engagement and results in enhancing students' participation in the classroom (Sherer \& Shea, 2011) and increasing students' achievement in learning (Jones \& Cuthrell, 2011). Moreover, Mullen and Wedwick (2008) stated that modern technology, e.g. Web 2.0 technology, needs to be implemented into the classroom learning process in order to develop the students' skills required in the new digital society. Therefore, primary teachers 
Irwan Koto, Teaching and Learning Science using YouTube Videos and Discovery Learning ...

have to combine video technology with appropriate learning goals and tasks (Krauskopf, Zahn \& Hesse, 2012).

In the use of YouTube videos as cognitive tools for student learning, the primary school teacher's adequate pedagogical knowledge to combine YouTube videos presentation with appropriate learning goals and tasks can affect the success of YouTube videos for student learning. The previous studies reported that teachers have to integrate their professional knowledge about teaching and their knowledge of technology (Webb \& Cox, 2004; Krauskopf, Zahn, \& Hesse, 2012).

In this study, the Technological Pedagogical Content Knowledge (TPCK) has been adopted as the theoretical framework and considered as an integrated part of teacher knowledge, namely pedagogical knowledge, and technological knowledge. However, this research focuses on technological pedagogical knowledge and TPCK (Mishra \& Koehler, 2006) since the two aspects can affect teacher decisions on selecting YouTube videos relevant to learning goals and tasks (Krauskopf, Zahn, \& Hesse, 2012). Therefore, this research uses the technological, pedagogical, and content knowledge (TPACK) framework to examine the effects of YouTube videos as an educational tool on the discovery learning process.

One of the learning strategies that promote students' engagement in the learning process is discovery learning. However, Shulman and Keisler cited in Mayer (2004) stated that guided discovery learning is more effective than pure discovery in terms of helping students construct knowledge used for making sense of new information and integrating new information with the knowledge base. Furthermore, the usage of guided discovery learning is more effective and efficient than a minimally guided instructional approach (Kirschner, Sweller \& Clark, 2006) because it provides the guidance needed by students to achieve the intended learning outcome (Mayer, 2004).

According to Reid, Zang, \& Chen (2003), three main interconnecting spheres involved to ensure effective discovery learning are (1) problem representation and hypothesis generation, (2) testing hypothesis with experiments; and (3) reflective abstraction and integration of the discovery experiences. To take into account the effective discovery learning, students involved in the research were guided to formulate the questions and generate hypotheses after watching YouTube videos.

In the current research, the discovery learning environment in the experimental group is generated in the form of the use of YouTube videos and discovery-learning tasks related to hands-activities whereas the discovery learning environment in the control group comprised discovery-learning tasks involving hands-on activities. However, the discovery learning process can inhibit learning when students have less knowledge and information about the topic being studied (Alfieri, Brooks, Aldrich, \& Tenenbaum, 2011). YouTube videos can be one 
of the alternative multimedia of teaching and learning to convey the explanations related to knowledge to be learned in the classroom.

There is growing interest in the provision of the learning environment by employing roleplaying, groups project and computer simulation are well documented (Cohen, 2008). However, several studies have examined YouTube videos as the discovery learning environment. To fulfill this knowledge gap, we examined the impact of YouTube videos as a discovery learning environment in primary school classrooms. Consequently, this research aims at broadening the existing body of knowledge by examining the impacts of incorporating an educational technology tool into the classroom.

The Revised Bloom's Taxonomy (RBT) is used to formulate the intended primary science curricular objectives. The RBT in this research is used in accordance with two reasons. Firstly, RBT accompanies the constructivist learning paradigms that require active teaching methods, such as discovery learning. Secondly, the RBT is intended to propose a twodimensional approach to map cognitive development with the knowledge dimension and cognitive process (Krathwohl, 2002). Hence, RBT has been adopted worldwide in the science curriculum framework, for example, the Indonesian curriculum (the 2013 curriculum).

Based on the aforementioned literature review, there is limited research examined the implications of YouTube video as effective instructional tools for enhancing content learning of science, particularly in the Indonesian learning context. However, the recent study conducted by Yusri, Rosida, Jufri, and Mantasiah (2018) recommended that YouTube videos should be considered as effective teaching resources in increasing student's academic motivation. Regarding student achievement, Prastiyo, Djohar, and Purnawan (2018) reported that the usage of YouTube integrated with the classroom gained greater learning outcomes compared with students using the internet. Therefore, this research can provide a new perspective regarding the usage of YouTube videos as educational tools.

\section{METHOD}

\section{Research Design}

In this research, the quantitative data were collected from public primary school students located in the urban area in North Bengkulu Regency. The data were analyzed by descriptive and inferential statistics techniques (Fraenkel \& Wallen, 2007) by using SPSS 22 statistic program (Pallant, 2007).

The research was designed to examine the effects of YouTube videos and discovery learning on students' cognitive achievements in terms of factual, conceptual, and procedural knowledge. Based on the intended objective, the research question was formulated as follows: Is there a significant difference, in terms of factual, conceptual and procedural knowledge, between the experimental group, which examines YouTube videos and 
Irwan Koto, Teaching and Learning Science using YouTube Videos and Discovery Learning ...

discovery learning, and the control group, which examines discovery learning and hands of activities?

The research employed a quasi-experimental research design with a pre-test and post-test control and experimental group. Two main reasons for employing the quasi-experimental design in this research are (1) the random choice of schools and classrooms is fairly unfeasible and (2) the intended objectives of this research is to evaluate the causal influence of the intervention on target population without random choice (Cohen, Manion \& Morrison, 2009).

There were 42 fifth-grade students, consisting of 18 male students and 24 female students, from a public primary school in North Bengkulu as one of the districts in Bengkulu province (Indonesia) who participated in the research. Both groups consisted of twenty-one students aged from 11 to 12 years. The learning process was conducted for two hours a week to teach science lessons in four weeks throughout the fall semester of the 2018-2019 Academic Year.

\section{Data Collection}

The data were collected using the Science Achievement Test (SAT). The SAT items were developed based on the 2013 curriculum and the science textbooks published in 2016 by the Indonesian Ministry of Education and Culture. The SAT comprises 16 Multiple Choice Questions (MCQs) and 4 essay questions that cover the concept of heat transfer. Based on the revised Bloom Taxonomy (Krathwohl, 2002), the allocation of knowledge dimension and cognitive level of item tests is presented in Table 1.

For MCQs, each item has four options with one correct answer and essay tests provide a rubric to score students' answers. The validity of the SAT is presented in terms of content and construct validity. The content validity of the SAT was validated by two experienced primary school teachers and one senior lecturer from the postgraduate Program of Elementary Education. They examined all items in terms of relevance, clarity, and simplicity. The experts' comments and corrections were utilized to revise the items to get the final form of instrument. Based on the expert judgment, the field-testing was conducted to 40 students in the 6 th graders who had already learned the concept of heat energy transfer.

Table 1. Knowledge Dimension and Cognitive Level, Item Correlation, Item Difficulties and Item Discrimination

\begin{tabular}{|c|c|c|c|c|c|}
\hline $\begin{array}{c}\text { Item } \\
\text { No }\end{array}$ & $\begin{array}{l}\text { Knowledge } \\
\text { Dimension }\end{array}$ & $\begin{array}{c}\text { Cognitive } \\
\text { Level }\end{array}$ & $\begin{array}{l}\text { Total-Item } \\
\text { Correlation }\end{array}$ & $\begin{array}{c}\text { Item } \\
\text { Difficulties(a) }\end{array}$ & $\begin{array}{c}\text { Item } \\
\text { Discrimination(b) }\end{array}$ \\
\hline 1 & \multirow{3}{*}{ Factual } & \multirow{3}{*}{ Understanding } & $0.389 *$ & 0.826 & 0.389 \\
\hline 2 & & & $0.387^{*}$ & 0.804 & 0.387 \\
\hline 3 & & & $0.571^{* *}$ & 0.702 & 0.571 \\
\hline 4 & Factual & Applying & $0.479 * *$ & 0.548 & 0.479 \\
\hline
\end{tabular}




\begin{tabular}{|c|c|c|c|c|c|}
\hline 5 & & & $0.471^{* *}$ & 0.604 & 0.471 \\
\hline 6 & & & 0.207 & 0.648 & 0.207 \\
\hline 7 & \multirow{3}{*}{ Factual } & \multirow{3}{*}{ Analyzing } & $0.521^{* *}$ & 0.578 & 0.521 \\
\hline 8 & & & 0.281 & 0.725 & 0.281 \\
\hline 9 & & & $0.418^{* *}$ & 0.382 & 0.481 \\
\hline 10 & \multirow{3}{*}{ Conceptual } & \multirow{3}{*}{ Understanding } & $0.476^{* *}$ & 0.678 & 0.476 \\
\hline 11 & & & $0.357^{*}$ & 0.348 & 0.357 \\
\hline 12 & & & $0.468^{* *}$ & 0.584 & 0.468 \\
\hline 13 & \multirow{2}{*}{ Conceptual } & \multirow{2}{*}{ Applying } & $0.427^{* *}$ & 0.552 & 0.427 \\
\hline 14 & & & $0.468^{* *}$ & 0.719 & 0.468 \\
\hline 15 & \multirow{3}{*}{ Conceptual } & \multirow{3}{*}{ Analyzing } & 0.299 & 0.454 & 0.299 \\
\hline 16 & & & 0.291 & 0.602 & 0.311 \\
\hline 17 & & & $0.797^{*}$ & 0.549 & 0.493 \\
\hline 18 & \multirow{3}{*}{ Procedural } & \multirow{2}{*}{ Recalling } & $0.804^{* *}$ & 0.525 & 0.334 \\
\hline 19 & & & $0.326^{*}$ & 0.547 & 0.374 \\
\hline 20 & & Understanding & $0.376^{*}$ & 0.722 & 0.394 \\
\hline Note: & \multicolumn{5}{|c|}{$\begin{array}{l}{ }^{*} p<0.05 ; * * p<0.05 \\
\text { (a): The item difficulty index }(p) \text { is a measure of the difficulty of a single item test and it is computed by the } \\
\text { formula: } p=\frac{N_{l}}{N}\left(N_{l}=\text { number of correct responses on the item and } N=\text { the total number of students. }\right. \\
\text { (b): The item discrimination index (D) is a measure of the discriminatory power of each item test and the } \\
\text { formula is used to calculate it: } D=\frac{N_{H}-N_{L}}{N} \text { ( } \mathrm{H} \text { and } \mathrm{L}: \text { a high group dan a low group respectively). }\end{array}$} \\
\hline
\end{tabular}

After conducting the instrument test using formula KR-20 and Cronbach's alpha, the internal consistency of a 24-MCQs test and a 4-essay test were verified with the value of 0.74 and 0.70 respectively. According to Fraenkel and Wallen (2007), a reliability coefficient of 0.74 and 0.70 fulfilled the level of reliability because it should be at least 0.70 . The final item pool that has a relatively low degree of reliability may be caused by (1) the number of tasks in the test, (2) some items are too hard or too easy for students, and (3) the spread of scores gained by the item pool.

Table 1 shows four MCQs items in the test were excluded since the validity indexes were less than 0.30. The items were removed from the item pool used in the research as follows: two items from factual and conceptual knowledge respectively. The excluded items did not affect the content validity of the achievement scale. The data in Table 1 shows that the item difficulty indices were ranging from 0.348 to 0.826 while the Item discrimination varied from 0.207 to 0.571 . Therefore, the final item pool used for collecting data was a 16-item MCQs and 4-item essay questions.

Before carrying out the learning process, YouTube videos were selected in accordance with the intended instructional purposes, and the students' characteristics and interests (Berk, 2009). Another criterion for choosing YouTube as a video clip is the length of the video 
Irwan Koto, Teaching and Learning Science using YouTube Videos and Discovery Learning ...

because shorter videos (about 10 minutes) are more engaging compared to longer YouTube videos (Guo, Kim and Rubin, 2014), Thus, YouTube video clips which are used in this research was retrieved from https://www.youtube.com/watch?kuFWbA-k (accessed May 24, 2019).

At the beginning of treatment, the researchers divided students into heterogeneous groups of 5 students (one group had four students) in terms of gender and academic achievement. Furthermore, a pre-test was conducted to both the experimental and control groups. The students answered 20 questions in class for 25 minutes before conducting the teaching and learning process in both groups.

The experimental group was given a science lesson with guided discovery as a teaching method and YouTube video as ICT multimedia, while the control group was taught with guided discovery. The experimental group was taught by one of the researchers who had 5years of teaching experience, while the control groups were taught by a classroom teacher who had 8-years of teaching experience. Furthermore, after the teaching of the concept of heat energy transfer, a post-test was conducted to the treatment and control group.

\section{RESULTS}

Since there were only two classes in the fifth grade, homogeneity of variances was tested for the previous science achievement scores. Levene's test indicated the equality of variance for the groups (Levene: $0,229, p(0.635)>0.05)$. It can be said that the academic levels of students in both groups were approximately equal variances. As a result of that, the classes were randomly assigned to the experimental and control groups.

Table 2. Kolmogorov-Smirnov Test of Goodness of Fit

\begin{tabular}{|c|c|c|c|c|c|c|c|}
\hline \multirow{2}{*}{ Variables } & \multicolumn{2}{|c|}{$\begin{array}{l}\text { Kolmogorov- } \\
\text { Smirnov Test (*) }\end{array}$} & \multicolumn{2}{|c|}{$\begin{array}{c}\text { Shapiro-Wilk } \\
\text { Test }\end{array}$} & \multirow{2}{*}{$\begin{array}{l}\text { Median } \\
\text { (Mean) }\end{array}$} & \multirow{2}{*}{$\begin{array}{l}\text { Skewness } \\
\text { (Kurtosis) }\end{array}$} & \multirow{2}{*}{ Conclusion } \\
\hline & Statistic & $\begin{array}{c}\mathrm{p}- \\
\text { value }\end{array}$ & Statistic & $\begin{array}{c}\mathrm{p}- \\
\text { value }\end{array}$ & & & \\
\hline $\begin{array}{c}\text { Factual } \\
\text { Knowledge }\end{array}$ & 0.219 & 0.000 & 0.807 & 0.000 & $\begin{array}{c}31.2 \\
(33.303)\end{array}$ & $\begin{array}{c}-0.149 \\
(-1.218)\end{array}$ & $\begin{array}{l}\text { Not normally } \\
\text { distributed }\end{array}$ \\
\hline $\begin{array}{l}\text { Conceptual } \\
\text { Knowledge }\end{array}$ & 0.151 & 0.018 & 0.938 & 0.024 & $\begin{array}{c}37.5 \\
(39.067)\end{array}$ & $\begin{array}{l}-0.099 \\
(-1.070)\end{array}$ & $\begin{array}{l}\text { Not normally } \\
\text { distributed }\end{array}$ \\
\hline $\begin{array}{l}\text { Procedural } \\
\text { Knowledge }\end{array}$ & 0.179 & 0.002 & 0.894 & 0.001 & $\begin{array}{c}50.0 \\
(52.544) \\
\end{array}$ & $\begin{array}{l}-0.285 \\
(0.270) \\
\end{array}$ & $\begin{array}{c}\text { Not normally } \\
\text { distributed }\end{array}$ \\
\hline
\end{tabular}

To better visualize the difference between the distribution of factual knowledge, conceptual knowledge, and procedural knowledge scores, the score distribution is also shown in the form of box and whisker plots presented in Figure 1. 
Boxplot presents a graphical picture to indicate whether or not the data violates the assumption of normality (Abdi \& Molin, 2007). As seen in Figure 1, the normality assumption is violated so that parametric statistical analysis can be used to test the formulated hypothesis.

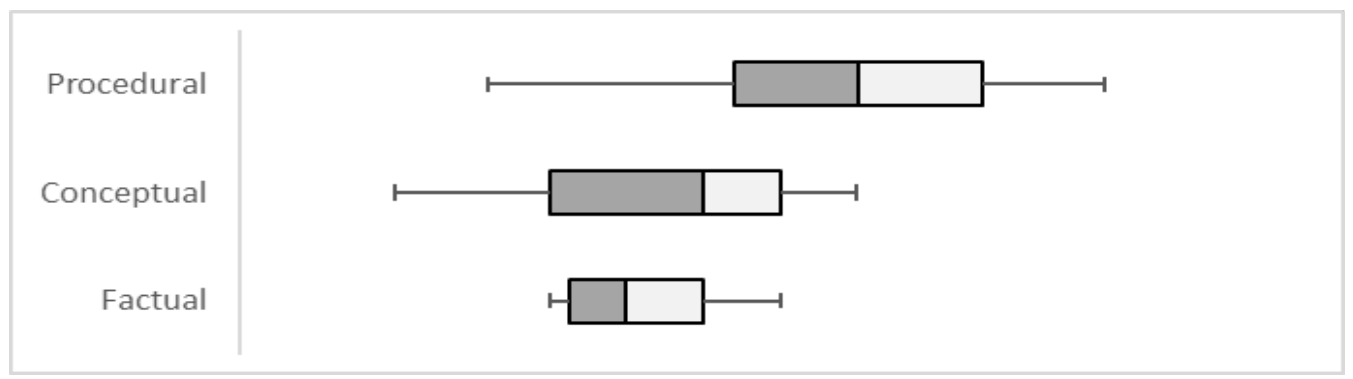

Figure 1. Boxplots and whisker of Factual, Conceptual and Procedural Scores

Although, boxplot is the common graphical methods that can be used to examine the normality assumption, the numerical methods such as the KS test of goodness of fit has to be performed first in order to make inference about the normality of the data (Razali \& Wah, $2011)$ for supporting boxplots. The SW test was performed with the KS test. Table 2 shows that there was enough evidence to conclude that the pre-test scores were not normally distributed due to the $p$-value less than the threshold $(\alpha=0.05)$.

The research was conducted in a small sample $(n \leq 30)$ and the pre-test scores in two groups did not come from a normally distributed population. Therefore, for testing whether or not pre-and post-test SAT score differences changed in terms of the treatment groups, the MannWhitney-Wilcoxon test (MWW) preferred to be performed (Fay \& Proschan, 2010). The pre and post-test data obtained from both groups were compared using MWW test on an alpha $(\alpha)$ significant level of 0.05 .

Table 3. Mann-Whitney, Wilcoxon Wilcoxon-Wilson, Z-value, p-value, Median, and Mean Rank for Pre and Post Test Scores.

\begin{tabular}{|c|c|c|c|c|c|c|c|c|}
\hline Variables & Measure & Groups & $\begin{array}{l}\text { Mann- } \\
\text { Whitney }\end{array}$ & $\begin{array}{c}\text { Wilcoxon } \\
\text { W }\end{array}$ & $\begin{array}{c}\text { Z- } \\
\text { value }\end{array}$ & $\begin{array}{c}p- \\
\text { value }\end{array}$ & Median & $\begin{array}{l}\text { Mean } \\
\text { Rank }\end{array}$ \\
\hline \multirow[b]{3}{*}{ Factual } & \multirow[t]{2}{*}{ Pre-test } & \multirow{2}{*}{$\begin{array}{l}\text { Treatment } \\
\text { Control }\end{array}$} & \multirow{2}{*}{176.500} & \multirow{2}{*}{407.500} & \multirow{2}{*}{-1.186} & \multirow{2}{*}{0.236} & 31.2 & 23.60 \\
\hline & & & & & & & 31 & 18 \\
\hline & Post-test & $\begin{array}{c}\text { Treatment } \\
\text { Control }\end{array}$ & 133.500 & 364.500 & -2.767 & 0.006 & 37.5 & $\begin{array}{l}25.64 \\
17.36\end{array}$ \\
\hline \multirow{4}{*}{ Conceptual } & \multirow[t]{2}{*}{ Pre-test } & \multirow{2}{*}{$\begin{array}{c}\text { Treatment } \\
\text { Control }\end{array}$} & \multirow{2}{*}{213.500} & \multirow{2}{*}{444.500} & \multirow{2}{*}{-0.178} & \multirow{2}{*}{0.859} & 3 & 17 \\
\hline & & & & & & & 37.5 & \\
\hline & \multirow[t]{2}{*}{ Post-test } & \multirow{2}{*}{$\begin{array}{c}\text { Treatment } \\
\text { Control }\end{array}$} & \multirow{2}{*}{136.000} & \multirow{2}{*}{367.00} & \multirow{2}{*}{-2.190} & \multirow{2}{*}{0.029} & 43.7 & 25.52 \\
\hline & & & & & & & 37.5 & 17.48 \\
\hline \multirow{3}{*}{ Procedural } & \multirow{2}{*}{ Pre-tes† } & \multirow{2}{*}{$\begin{array}{c}\text { Treatment } \\
\text { Control }\end{array}$} & \multirow{2}{*}{194.00} & \multirow{2}{*}{425.00} & \multirow{2}{*}{-0.697} & \multirow{2}{*}{0.486} & 50.0 & 22.76 \\
\hline & & & & & & & 50.0 & 20.24 \\
\hline & Post-test & $\begin{array}{c}\text { Treatment } \\
\text { Control }\end{array}$ & 74.000 & 305.00 & -3.784 & 0.000 & $\begin{array}{l}75.0 \\
50.0\end{array}$ & $\begin{array}{r}28.48 \\
14.52\end{array}$ \\
\hline
\end{tabular}


Irwan Koto, Teaching and Learning Science using YouTube Videos and Discovery Learning ...

Note: Statistically significant (significance defined as $p<0.05$ ).

\section{Research Hypothesis}

The main objective of this research is to investigate the parametric effect of discovery learning combined with YouTube videos on student achievement. Their achievement was evaluated by the SAT test about heat transfer concepts. To achieve the objective, the null hypothesis defined below is formulated and tested statistically as the following.

Ho: there is no significant effect of YouTube videos and discovery learning on students' cognitive achievement in terms of factual, conceptual, and procedural knowledge.

The Mann-Whitney $U$ test was employed to test for differences in the median between the experimental and control groups. The SPSS 22 statistical package for Windows was used to analyze the data. The findings related to hypothesis testing are presented in Table 3.

Table 3 shows that the Mann-Whitney $U$ test revealed that there was a significant difference in the factual knowledge scores of students who are taught by the use of discovery learning with YouTube video (Mdn $=37.5 ; n=21)$ and by the use of discovery learning without YouTube video $(M d n=37.5 ; n=21), U=113.5 ; p=0.006$. Although the experimental group using YouTube video in the discovery learning environment had a higher score on mean rank $(=25.64)$ compared to the mean rank of the control group (7.36), the $r$-value $(0.18)$ indicated a small effect size based upon Cohen'd criteria (see Table 4).

Table 4. Z-score and Effect Size ( $N=42)$

\begin{tabular}{lcccc}
\hline \multirow{2}{*}{ Variables } & \multicolumn{2}{c}{ Z-score } & $\begin{array}{c}\text { Effect Size } \\
(r-\text { value })\end{array}$ & Category* \\
\cline { 2 - 4 } & Pre-test & Post-test & \\
\hline Factual & -1.186 & -2.767 & 0.18 & Small effect \\
Conceptual & -0.178 & -2.190 & 0.11 & Small effect \\
Procedural & -0.697 & -3.784 & 0.34 & Medium effect \\
\hline
\end{tabular}

Note: The effect size for the Mann-Whitney $U$ test is calculated: $r=\frac{|Z|}{\sqrt{N}}$

${ }^{*}$ Cohen'd criteria of 0.1 = small effect; 0.3 = medium effect; 0.5 = large effect (Sullivan \& Feinn, 2012).

Similarly, conceptual knowledge scores of primary school students (experimental group) who were taught by YouTube videos in discovery learning ( $M d n=43.7 ; n=21$ ) were higher than those of learning science without YouTube video ( $M d n=37.5 ; n=21)$. A Mann-Whitney $U$ test revealed that this difference was statistically significant, $U=136.0 ; Z=-2.19 ; p<0.029$. Based on Cohen's criteria (Table 4), the effect of YouTube video on student conceptual knowledge achievement was categorized as a small effect size $(r=0.11)$. Fergurson (2009) recommended the effect size should be more than 0.2 . 
A Mann-Whitney $U$ test was conducted to evaluate the hypothesis that students who were taught by discovery learning with YouTube videos had a higher score, on average than students who were taught by discovery learning without YouTube videos on procedural knowledge. The results of the $U$ test were statistically significant, $Z=-3.784 ; U=74.0 ; p<0.001$. Concerning effect size, the $r$-value was 0.34 . This would be counted as medium effect size (Sullivan \& Feinn, 2012). Table 4 shows data related to the Z-score and effect size as well as the category of effect size.

\section{DISCUSSION}

The findings revealed that the use of discovery learning and YouTube videos as educational technology tools in primary school science lesson helped students enhance cognitive achievement. After attending four weeks learning educational period, students in the experimental group became relatively successful in comprehending the heat transfer concepts than students in the control group.

The experimental and control groups increased relatively their median score by 6.3 and 6.2 in terms of factual knowledge and conceptual knowledge from pre-test to post-test. However, Table 3 depicts that students in the experimental group increased significantly their procedural knowledge score by 25.0 points whereas the control group was not increased from pre-test to post-test. Furthermore, in terms of procedural knowledge, the effectiveness of YouTube videos accompanied by guided discovery learning as a method to deliver heat transfer concepts gained medium effect $(r=0,34)$ compared to students learned in the discovery learning environment without YouTube videos.

\section{Assertion 1: Enhancing learning process or cognitive achievement}

The research result revealed the usage of YouTube videos as educational tools in a science lesson is more appropriate to increase students' participation in the learning process rather than to enhance students' cognitive achievement. This is in line with Berk (2009) who stated that YouTube videos can attract students' attention and to arouse students' curiosity. Furthermore, YouTube videos can also play a major role in enhancing the process of learning when it is used properly (Churchill, 2009). Besides, YouTube video has the potential to enhance the learning process not only by providing alternative means for students and learners to engage with their material but it is also able to strengthen the position of teachers by supporting the strength of their lesson structure and preparation (Berk, 2009).

Since "YouTube.com" as a platform has been launched in February 2005, YouTube becomes an online video-sharing website, which is the most popular in the world and the most visited site on the internet (Riley, 2017). In response to digital education for digital natives, teachers can use YouTube video in learning science and classroom environment for two reasons: (1) it is a relatively simple method of providing audiovisual material into the classroom, and (2) it 
Irwan Koto, Teaching and Learning Science using YouTube Videos and Discovery Learning ...

gives teachers more possibilities to provide various learning styles (i.e. audio and visual) for students [Koto, Harneli \& Winarni, 2018).

\section{Assertion 2: Influential factors towards the effectiveness of YouTube videos in a science lesson in primary school}

Related to the size of the effect, it is very important to decide to confirm that the usage of YouTube videos accompanied by discovery learning in science lessons has an important effect on factual, conceptual, and procedural knowledge. To examine how to explain the influential factors toward the effectiveness of YouTube videos in the learning process, the extent to which factual, conceptual and procedural knowledge can be explained by the use of YouTube videos in discovery learning, which is needed to be discussed (Téllez, Garcia, Corral-Verdugo, 2015).

In this research, the science topic delivered to fifth-graders was the heat transfer. The previous researchers' reports the heat transfer concept in term of heat and temperature concepts are one of the most difficult concepts of the science curricula at levels of primary schools (Bilgin, Nas, \& Çoruhlu, 2017), secondary (Yeo \& Zadnik,2001) and post-secondary education (Jasien \& Oberem, 2002). The source of difficulty is the different explanations of words like "heat capacity" and "heat flow", which flow from warmer to colder objects (Haglund, Jeppsson, \& Schönborn, 2015).

The previous research reported that most students believed that the concepts of heat and temperature can be used interchangeably (Paik, Cho, \& Go, 2007) since the two concepts are the most widely-used concepts in our everyday lives. Consequently, students are not able to understand the concepts of heat and temperature accurately, resulting in misunderstandings from them. Based on this perspective, the use of YouTube videos coupled with discovery learning is not suitable for learning difficult concepts such as heat transfer in primary school.

\section{CONCLUSION}

In conclusion, the research findings revealed that the experimental group showed various effects on the acquisition of factual, conceptual, and procedural knowledge. YouTube videos accompanied by discovery learning can the improvement of fifth-grade students' performances in terms of procedural knowledge rather than factual and conceptual knowledge.

This research has implications in a practical level related to teacher knowledge about video technology required in selecting YouTube videos since well-selected video material can affect student knowledge. 
Future studies can enhance the generalization of the results by using larger sample sizes. Moreover, there is a need for more studies on primary school students' perceptions regarding the implications of YouTube videos in learning science.

The current research is limited to several aspects. For example, participants do not present a broad and disperse population, and limited data collection instruments have been used whereas the use of questionnaires and interview may have added breadth and scope to study.

\section{ACKNOWLEDGMENTS}

The researchers would like to thank the fifth-grade students and classroom teachers who had participated voluntarily in this research. We also thank the principal who allowed us to research his school.

\section{REFERENCES}

Abdi, H., \& Molin, P. (2007). Lilliefors/Van Soest's test of normality. In Neil Salkind (Ed.). Encyclopedia of measurement and statistics. Thousand Oaks (CA): Sage.

Alfieri, L., Brooks, P. J. Aldrich, N. J. \& Tenenbaum, H. R. (2011). Does discovery-based instruction enhance learning? Journal of Educational Psychology, 103(1), 1-18.

Berk, R. A. (2009). Multimedia teaching with video clips: TV, Movies, YouTube, and $m$ tvU in the college classroom. International Journal of Technology in Teaching and Learning, 5(1), $1-21$.

Bilgin, K., A., Nas, S. E., \& Çoruhlu, T, Ş. (2017). The effect of fire context on the conceptual understanding of students: "The Heat-temperature". European Journal of Educational Studies, 3(5), 339-355.

Churchill, D. (2009). Educational application of web 2.0: Using blogs to support teaching and learning. Journal of Educational Technology, 40(1), 179-183.

Cohen, M. T. (2008). The effect of direct instruction versus discovery learning on the understanding of science lessons by second-grade students. NERA Conference Proceeding 2008, Paper 30. http://digitalcommons.ucon.edu_2008/30.

Cohen, L., Manion, L., \& M, K. (2009). Research methods in education (6th ed). London and New York. Routledge.

Fay, M. P., \& Proschan, M. A. (2010). Wilcoxon-Mann-Whitney or t-test? on assumptions for hypothesis tests and multiple interpretations of decision rules. Statistics Surveys, 4, 1-39.

Ferguson, J. C. (2009). An effect size primer: A Guide for clinician and researchers. Professional Psychology: Research and Practice, 40(5), 532-538.

Fraenkel, J. R. \& Wallen, N. E. (2007). How to design and evaluate research in education (6th ed), Mc Graw-Hill International Edition. New York, Ny. 10020.

Haglund, J., Jeppsson, F. \& Schönborn, K J. (2015). Taking on the heat: A narrative account of how infrared cameras invite instant inquiry. Research in Science Education. 1-28. doi:10.1007/s $11165-015-9476-8$. 
Irwan Koto, Teaching and Learning Science using YouTube Videos and Discovery Learning ...

Guo, P. J., Kim, J., \& Rubin, R. (2014). How video production affects student engagement: An Empirical study of MOOC videos. In Learning at scale. Retrieved June 14, 2019, from http://dx.doi.org/10.1145/2556325.25662.

Jaffar, A.A. (2012). YouTube: An Emerging tool in anatomy education. Anatomical Science Education, 5(3), 158-164. DOI: 10.1002/ase.128.

Jones, T. \& Cuthrell. (2011). YouTube: educational potentials and pitfalls. Computers in the Schools, 28(1), 75-85, DOI: 10.1080/07380569.2011.553149.

Jasien, P. G. \& Carter, G. E. (2002). Understanding of elementary concepts in heat and temperature among college students and K-12 teachers. Journal of Chemical Education, 79(7), 889-895.

Kirschner, P. A., Sweller, J. \& Clark. (2006). Why minimal guidance during instruction does not work: An Analysis of the failure of constructivist, discovery, problem-based, experiential, and inquiry-based teaching. Educational Psychologist, 41 (2), 75-86.

Koto, I., Harneli, M., \& Winarni, E. W. (2018). Primary school teacher strategy to promote student engagement in science lessons. Advances in Social Science, Education and Humanities Research, 303, 122-127.

Krauskopf, K., Zahn, C., \& Hesse, F. W. (2012). Leveraging the affordances of YouTube: The role of pedagogical knowledge and mental models of technology functions for lesson planning with technology. Computers \& Education, 58. 194-1206.

Krathwohl, D. R. (2002). A Revision of Bloom's taxonomy: An Overview. Theory into Practice, $41(4)$. Autumn.

Mayer, R. E. (2004). Should there be a three-strikes rule against pure discovery learning? The case for guided methods of instruction. American Psychologist, 59 (1), 14-19.

Mishra, P. \& Koehler, M., J. (2006). Technological pedagogical content knowledge: A Framework for teacher knowledge. Teachers College Record, 108(6). 1017-1054.

Mullen, R., \& Wedwick, L. (2008). Avoiding the digital abyss: Getting started in the classroom with youtube, digital stories, and blogs. Clearing House, 82(2), 66-9.

Pallant, J. (2007). SPSS survival manual: A Step by step guide to data analysis using SPSS for windows, (3rd ed). Mc Graw-Hill, England.

Paik, S. H., Cho, B. K., \& Go, Y. M. (2007). Korean 4-tol 1-year-old student conceptions of heat and temperature. Journal of Research in Science Teaching, 44, 284-302.

Prastiyo, W., Djohar, A., \& Purnawan (2018). Development of YouTube integrated google classroom-based E-learning media for the light-weight vehicle engineering vocational high school. Jurnal Pendidikan Vokasi. 8(1), 53-66.

Razali, N. M \& Wah, Y. B. (2011). Power comparisons of Shapiro-Wilk, Kolmogorov-Smirnov, Lilliefors and Anderson-Darling tests. Journal of Statistical Modeling and Analytics, 2(1), $21-33$

Reid, D. J., Zhang, J. \& Chen, Q. (2003). Supporting scientific discovery learning in a simulation environment. Journal of Computer Assisted Learning, 19, 9-20.

Riley, J. (2017). Integrating YouTube videos in online teacher education courses. Journal of Teaching and Learning with Technology, 6(1), 81-84. DOI: 10.14434/jotlt. v6. n1.19526. 
Sherer, P., Shea, T. (2011). Using online video to supporting student learning and engagement. College Teaching, 59, 56-59.

Sullivan, G. M. \& Feinn, R. (2012). Using effect size-or why the $p$ value is not enough. Journal of Graduate Medical Education. 279-282. DOI: 10.4300/JGME-D-12-00156.1

Téllez, A., Garcia, C. H., \& Corral-Verdugo. (2015). Effect size, confidence intervals, and statistical power in psychological research. Psychology in Russia: State of the Art, 8(3), 27-45.

Yeo, S., \& Zadnik, M. (2001). Introductory thermal concept evaluation: Assessing student's understanding. The Physics Teacher, 39, 496-504.

Yusri, Y., Rosida, A., Jufri, J., \& Mantasiah, R. (2018). Efektivitas penggunaan media YouTube berbasis various approaches dalam meningkatkan motivasi belajar bahasa Inggris. Eralingua: Jurnal Pendidikan Bahasa Asing dan Sastra

Webb, M., \& Cox, M. (2004). A review of pedagogy related to information and communications technology. Technology, Pedagogy and Education, 13, 235-286. DOI: $10.1080 / 14759390400200183$ 